\title{
Correlation of knee ultrasonography and Western Ontario and McMaster University (WOMAC) osteoarthritis index in primary knee osteoarthritis
}

\author{
Gehan S. Seifeldein ${ }^{1 *} \mathbb{B}$, Abolhasan Haseib ${ }^{1}$, Hosam A. Hassan ${ }^{1}$ and Ghada Ahmed²
}

\begin{abstract}
Background: Knee osteoarthritis (KOA) is the most common cause of a painful joint, and it is associated with significant health economic consequences. About literature, $\mathrm{KOA}$ is usually diagnosed according to changes seen on conventional radiography, but the radiographic features of OA do not correlate with its symptoms. Nowadays, ultrasonography is becoming a non-invasive imaging tool for $\mathrm{OA}$ in the clinical setting. Thus, the purpose of this study was to evaluate the correlation between musculoskeletal ultrasound (MSK US) and the Western Ontario and McMaster University (WOMAC) osteoarthritis index findings in patients with primary knee osteoarthritis (KOA).

Methods: Between August 2015 and October 2017, 50 patients with a mean age of $46.72 \pm 9.12$ years who fulfilled the American College of Rheumatology (ACR) criteria for KOA were included. All the patients underwent a clinical assessment with the calculation of the WOMAC index, and they underwent knee US examination and conventional radiography (CR). Spearman's rho was used to assess the association between MSK US findings and the WOMAC index.

Results: The mean pain score was $10.08 \pm 2.89$, stiffness was $3.34 \pm 1.72$, physical function was $26.26 \pm 9.6$, and the total WOMAC score was $39.68 \pm 12.83$. Forty-seven knees showed radiographic femorotibial degenerative signs. The mean thicknesses of the ultrasound-measured articular cartilage of the medial condyle (MC), intercondylar notch area (IA), and lateral condyle $(\mathrm{LC})$ were $0.23 \pm 0.60 \mathrm{~cm}, 0.33 \pm 0.69 \mathrm{~cm}$, and $0.30 \pm 0.81 \mathrm{~cm}$, respectively. The US findings also included suprapatellar joint effusion (50\%), medial meniscal extrusion (40\%), and osteophytes (70\%). A positive correlation was found between the mean articular cartilage thickness of the IA, mean pain score, and stiffness subclasses of the WOMAC score $(r=0.342, p=0.015 ; r=0.414, p=0.003)$, respectively.
\end{abstract}

Conclusions: The severity of KOA, based on articular cartilage thickness, showed good correlation with the pain and stiffness subclasses of the WOMAC score.

Keywords: Knee, Osteoarthritis, WOMAC, Ultrasound

\section{Background}

Knee osteoarthritis (KOA) is the most common joint disease. The prevalence appears to be as high as $26 \%$ of women and $12 \%$ of men over 70 years old [1, 2]. OA is viewed today as the clinical and pathological outcome of a range of disorders that result in degenerative, progressive

\footnotetext{
* Correspondence: gehanseifeldein@aun.edu.eg; http://www.aun.edu. eg/membercv.php?M_ID=2319; https://scholar.google.com.eg/citations?user= vo_mjFoAAAAJ\&hl=en

${ }^{1}$ Diagnostic Radiology Department, Faculty of Medicine, Assiut University Hospital, Assiut University, Assiut, Egypt

Full list of author information is available at the end of the article
}

structural, and functional failure of synovial joints [3]. OA occurs when the dynamic equilibrium between the breakdown and repair of joint tissues is overwhelmed, which eventually causes pain, physical disability, and psychological distress [4].

Clinical examination is used to diagnose KOA [5]. At the early phase of $\mathrm{OA}$, the condition can be asymptomatic. Then at the later phase, clinical assessment of patients with joint symptoms, disabling pain, and joint dysfunction allows evaluating limitation in the range of movement, deformities, and instability. For the assessment of joint 
dysfunction and symptoms, the Western Ontario and McMaster Universities (WOMAC) osteoarthritis index is widely used in clinical studies to assess the outcomes of patients with osteoarthritis. The WOMAC comprises 24 questions covering the pain, stiffness, and physical functioning of the joint [6-9].

Traditionally, OA structural changes have been assessed with plain anteroposterior weight-bearing radiography. Conventional radiographic assessment of KOA relies mainly on the evaluation of both osteophytes and joint space narrowing [10]. The severity of radiographic OA can be estimated by the widely used Kellgren-Lawrence grading classification. The main disadvantage of plain radiography is its lack of soft tissue depiction $[11,12]$.

Magnetic resonance imaging (MRI) has a role in the assessment of the knee OA as it allows direct assessment of the articular cartilage, but it is not widely available [13-15]. Musculoskeletal ultrasound (MSK US) is a well-established imaging modality for the evaluation of different musculoskeletal abnormalities, such as rheumatic diseases, soft tissue lesions, and joint problems [16$18]$. But it has been applied to OA less frequently as reported by the European Society of Musculoskeletal Radiology (ESSR) consensus who reported that ultrasound examination for KOA was included with an evidence level of $B$ and indication grade of 1 (if other imaging techniques are not appropriate) [19].

Nowadays, MSK US has acquired an increasing role in the assessment of joint and periarticular abnormalities in OA. It can depict inflammatory and structural changes at different peripheral joint sites, and it is helpful for guiding local procedures that can be easily and safely performed with optimal patient tolerance. MSK US is a feasible imaging modality that has become a bedside procedure in clinical rheumatology practice, thus filling the gap between clinical and radiographic evaluations of patients with OA [20]. Although there is increasing evidence of the validity of MSK US for detecting structural pathology in inflammatory arthritis, more work is required to develop standardized definitions of pathology and demonstrate the validity of ultrasonography in osteoarthritis [21], and standardization of the scanning procedures is an important requisite for skilled and safe use [22].

The aim of this work was to evaluate the correlation between MSK US and the WOMAC osteoarthritis index findings in patients with primary knee osteoarthritis.

\section{Methods}

\section{Patients}

Between August 2015 and October 2017, a cross-sectional study was conducted on 50 patients who had primary knee OA and fulfilled the American College of Rheumatology (ACR) criteria for knee OA at least three out of six of the following criteria: age $>50$ years, morning stiffness
$<30$ min, crepitus, bony tenderness, bony enlargement, and no palpable warmth [23]. Exclusion criteria included secondary OA, history of previous knee surgery, and intra-articular injection of corticosteroids or hyaluronic acid. The patients were recruited from rheumatology and rehabilitation outpatient clinics. All patients underwent a clinical assessment and calculation of the WOMAC index by one rheumatologist. All the included patients underwent plain anteroposterior weight-bearing radiographs of the knees and MSK US of the more symptomatic knee in the Diagnostic Radiology Department. Informed consent was obtained from all patients, and the approval of the ethics committee was obtained.

\section{Clinical examination}

All patients underwent a clinical assessment by a rheumatologist and calculation of the WOMAC index for the more symptomatic knee. Symptomatic OA is generally defined by the presence of pain, aching or stiffness in a joint with radiographic OA corresponding to Kellgren-Lawrence scale grade of $\geq 2$ [24].

The WOMAC index for each patient was calculated based on the Likert version. The index is divided into three subscales [25-27]:

- Pain (five items): during walking; using stairs; in bed, sitting, or lying; and standing upright

- Stiffness (two items): after first waking and later in the day

- Physical function (17 items): using stairs, rising from sitting, standing, bending, walking, getting in/out of a car, shopping, putting on/taking off socks, rising from bed, lying in bed, getting in/out of bath, sitting, getting on/off toilet, heavy domestic duties, light domestic duties

The Likert version of the WOMAC is assigned a numerical score of $0-4$ corresponding to severity (none, mild, moderate, severe, and extreme). The minimum score is 0 , and the maximum score is 96 (20 points for pain, 8 points for joint stiffness, and 68 points for physical function) [5].

\section{Ultrasound examination}

MSK US of the most affected knee was performed by two radiologists with 15 and 6 years of experience in MSK US, respectively, who were blinded to the clinical presentation and WOMAC indexes of the patients. All ultrasound assessments were gray-scale imaging performed using a high-frequency $10-$ to $12-\mathrm{MHz}$ linear transducer (LOGIQ 5, GE Healthcare). The patient was placed in the supine position and scanned in the anterior suprapatellar transverse plane immediately above the patella with $90^{\circ}$ flexion of the knee [28]. The thickness of 
the femoral articular cartilage was measured at the midportion of the medial (MC) and lateral (LC) femoral condyles and at the intercondylar notch area (sulcus) (IA). The cartilage thickness was measured in centimeters $(\mathrm{cm})$ as the distance between the thin hyperechoic line at the synovial space/cartilage interface and the sharp hyperechoic line at the cartilage-bone interface [29]. All measurements were performed by both radiologists, and the one value was performed in consensus for the study.

In addition, the joint was scanned in the anterior longitudinal and transverse planes according to the European League Against Rheumatism (EULAR) [30] and OMERACT guidelines for knee ultrasound [31]. Image analysis was performed for the following:

1- Osteophytes were defined as elevated step-up bony fragments close to the joint space

2- Effusion appeared as a $\geq 4$ - $\mathrm{mm}$ anechoic intraarticular area in the suprapatellar recess that was displaceable and compressible on the longitudinal scan with full extension. It is graded into minimal, mild, and severe

3- Synovial hypertrophy appeared as hypoechoic intraarticular tissue $\geq 2 \mathrm{~mm}$ in the suprapatellar recess with full extension that was not displaceable and was poorly compressible

4- Baker's cyst appeared as an anechoic area between the semimembranosus and medial gastrocnemius tendon when the patient was evaluated in a prone position

5- Meniscal protrusion out of the joint space $>3 \mathrm{~mm}$ from the joint line was evaluated at the medial joint space with the knee in full extension on the longitudinal scan

\section{X-ray interpretation}

All the included patients underwent plain anteroposterior weight-bearing radiography of the more affected knee. The knee radiographs were read by another radiologist who was blinded to the clinical presentation, WOMAC index, and ultrasound findings. The radiographs were evaluated according to the KellgrenLawrence (K-L) grading system [11]. The original definitions of the K-L scale were used as follows: grade 0-no pathological features; grade 1-doubtful narrowing of joint space and possible osteophytic lipping; grade -2 , definite osteophytes and possible narrowing of joint space; grade 3-moderate multiple osteophytes, definite narrowing of joint space and some sclerosis and possible deformity of bony ends; grade 4-large osteophytes, marked narrowing of joint space, severe sclerosis, and definite deformity of bone ends [11].

\section{Statistical analysis}

The statistical analysis was performed using the Statistical Package for Social Science version 16 (SPSS, Inc., Chicago, IL, USA). The data were described as percentages for nominal variables and mean \pm standard deviation for continuous variables. The normal distribution of continuous variables was tested using the Kolmogorov-Smirnov test. Student's $t$ test was used to compare normally distributed data, and the Mann-Whitney $U$ test was used to compare non-normally distributed data. The $\chi^{2}$ test was used to compare categorical variables. Spearman's correlation coefficients were used to analyze the association between clinical and US findings. Statistical significance was set at $p<0.05$.

\section{Results}

\section{Demographic data}

The included patients comprised 30 females and 20 males, and their ages ranged from 27 to 62 years with a mean age of $46.72 \pm 9.12$ years. The male-to-female ratio was $2: 3$, and the predominant age group was $40-45$ years. Their mean BMI was $32.64 \pm 5.14 \mathrm{~g} / \mathrm{m}^{2}$. The patients' demographic data are summarized in Table 1 and Table 2.

\section{WOMAC index}

For the 50 studied patients, pain scores ranged from 4 to 16 , stiffness scores ranged from 0 to 6 , physical function ranged from 2 to 46 , and the total score ranged from 10 to 67 .

\section{Knee MSK US results}

The mean thicknesses of the articular cartilage of the MC, IA, and LC were $0.23 \pm 0.60$ (range $0.12-0.37$ ) $\mathrm{cm}, 0.33 \pm$ 0.69 (range $0.17-0.47$ ) $\mathrm{cm}$, and $0.30 \pm 0.81$ (range 0.17$0.59) \mathrm{cm}$, respectively (Fig. 1).

No significant difference was found between men and women regarding the thickness of femoral condyle articular cartilage $(p>0.05)$. No correlation was found between the BMI and thickness of articular cartilage ( $p>0.05$; Table 3$)$.

Other US findings were effusion $(n=25,50 \%)$, synovitis $(n=4,8 \%)$, osteophytes $(n=35,70 \%)$, medial meniscal extrusion $(n=20,40 \%)$, and Baker's cyst $(n=13$, 26\%) (Figs. 1 and 2).

\section{Plain radiographs of knees}

Forty-seven knees showed radiographic femorotibial degenerative signs represented as grade $0(n=3,6 \%)$, grade $1(n=2,4 \%)$, grade $2(n=35,70 \%)$, and grade $3(n=10$, 20\%) (Fig. 1).

\section{Association between WOMAC index and MSK US findings and K-L grading}

A moderate positive linear correlation was found among the total pain and stiffness subclasses and total score of 
Table 1 Demographic clinical data of 50 patients with OA

\begin{tabular}{lll}
\hline Variable & No. & Percentage \\
\hline Affected knee & 28 & 56.0 \\
Right & 22 & 44.0 \\
Left & & \\
Swelling & 42 & 84.0 \\
No & 5 & 10.0 \\
Mild & 3 & 6.0 \\
Moderate & & \\
Crepitus & 40 & 80.0 \\
Fine & 10 & 20.0 \\
Coarse & & \\
Tenderness & 19 & 38.0 \\
None & 19 & 38.0 \\
On the joint line & 5 & 10 \\
On multiple points & 1 & 2.0 \\
On the medial compartment & 1 & 2.0 \\
At the joint line and suprapatellar line & 5 & 10.0 \\
On all joints & & \\
Warmth & & 16.0 \\
Yes & & 84.0 \\
No & & \\
\hline
\end{tabular}

WOMAC index and thickness of IA $(r=0.342, p=0.015$; $r=0.414, p=0.003$; and $r=0.322, p=0.022$, respectively) (Fig. 3). No correlation was found among the WOMAC subclasses and the thickness of MC and LC $(p>0.05)$, as shown in Table 3.

Regarding gender, the total pain subclass of the WOMAC index had a significant association with the thickness of IA in men $(r=0.540, p=0.014)$, but the total stiffness subclass of the WOMAC index showed a significant association with the thickness of IA in

Table 2 WOMAC index subclasses and clinical examination values

\begin{tabular}{lll}
\hline Variable & Range & Mean \pm SD \\
\hline WOMAC index (Likert scale) & & \\
$\quad$ Pain & $4-16$ & $10.08 \pm 2.89$ \\
Stiffness & $0-6$ & $3.34 \pm 1.72$ \\
Physical function & $2-46$ & $26.26 \pm 9.6$ \\
Total score & $10-67$ & $39.68 \pm 12.83$ \\
BMI (kg $\backslash \mathrm{m}^{2}$ ) & $26-46.18$ & $32.64 \pm 5.14$ \\
C/O duration (year) & $1-10$ & $3.53 \pm 2.99$ \\
Ext. ROM (degree) & $0-5$ & $0.90 \pm 1.77$ \\
Quadr. circ. (cm) & $40-63$ & $51.86 \pm 6.01$ \\
\hline BMI body mass index, C/O complaint, Ext. ROM degree of extension range of \\
motion, Quadr. Circ. quadriceps circumference
\end{tabular}

women $(r=0.456, p=0.011)$. No association between the WOMAC subclasses and K-L grading was found.

A statistically significant negative association between the $\mathrm{MC}$ thickness and K-L grading $(r=-0.353, p=0.012)$ was observed.

There was a statistically significant difference in the total pain score subclass of the WOMAC index between the different degree of effusion, $\chi^{2}(2)=4.579, p=0.032$, with a mean rank pain score of 13.66 for minimal effusion, and 23.38 for moderate/severe effusion.

\section{Discussion}

Knee osteoarthritis (KOA) is a prevalent musculoskeletal disease that usually causes pain and disability [32]. In the current work, the study population was predominantly females, the highest frequency age group was between 40 and 45 years, and $70 \%$ of the patients had grade 2 OA changes according to the K-L grading. Their mean BMI was $32.64 \pm 5.14 \mathrm{~g} / \mathrm{m}^{2}$. According to the results of Kaban et al. [33], the loss of cartilage thickness during the premenopausal period continues in postmenopausal women with OA. Furthermore; previous studies [34] reported that obesity was one of a robust risk factor for KOA.

In the current study, a positive linear correlation was found among the total pain and stiffness subclasses of the WOMAC index and the thickness of the IA, similar to that reported in the study by Malas et al. [35]. The literature suggests that this association can be explained by pathological changes affecting synovial tissue or subchondral bone or both, which may have an important role in the pain and functional impairment associated with a clinical flare-up of OA [36].

A good correlation between ultrasound and clinical findings regarding synovial inflammation and the progression of structural damage has been suggested by Chen et al. [37] and Razek and El-Basyouni [38] as patients with cartilage changes, osteophytes, and synovial thickening have a higher WOMAC index and present with worse clinical symptoms. Additionally, Chen et al. found a positive linear association between ultrasound grading and the total score/pain subscale of the WOMAC [37]. The large, cross-sectional, multinational EULAR study [30] demonstrated that synovial inflammation (either synovial hypertrophy or effusion) was very common and much more frequently detected with the US than by clinical examination ( $47 \%$ vs. $30 \%$ ); this finding is similar to those of the current work (58\% vs. 16\%).

In addition, our results supported Abd El Monaem et al. [39] and Cubukcu et al. [40], who reported that WOMAC scores were not related to the $\mathrm{K}-\mathrm{L}$ grading scale. Conversely, previously published data have shown some contradictory results; examples include Serban et al. [41], who stated that the K-L score showed a good 


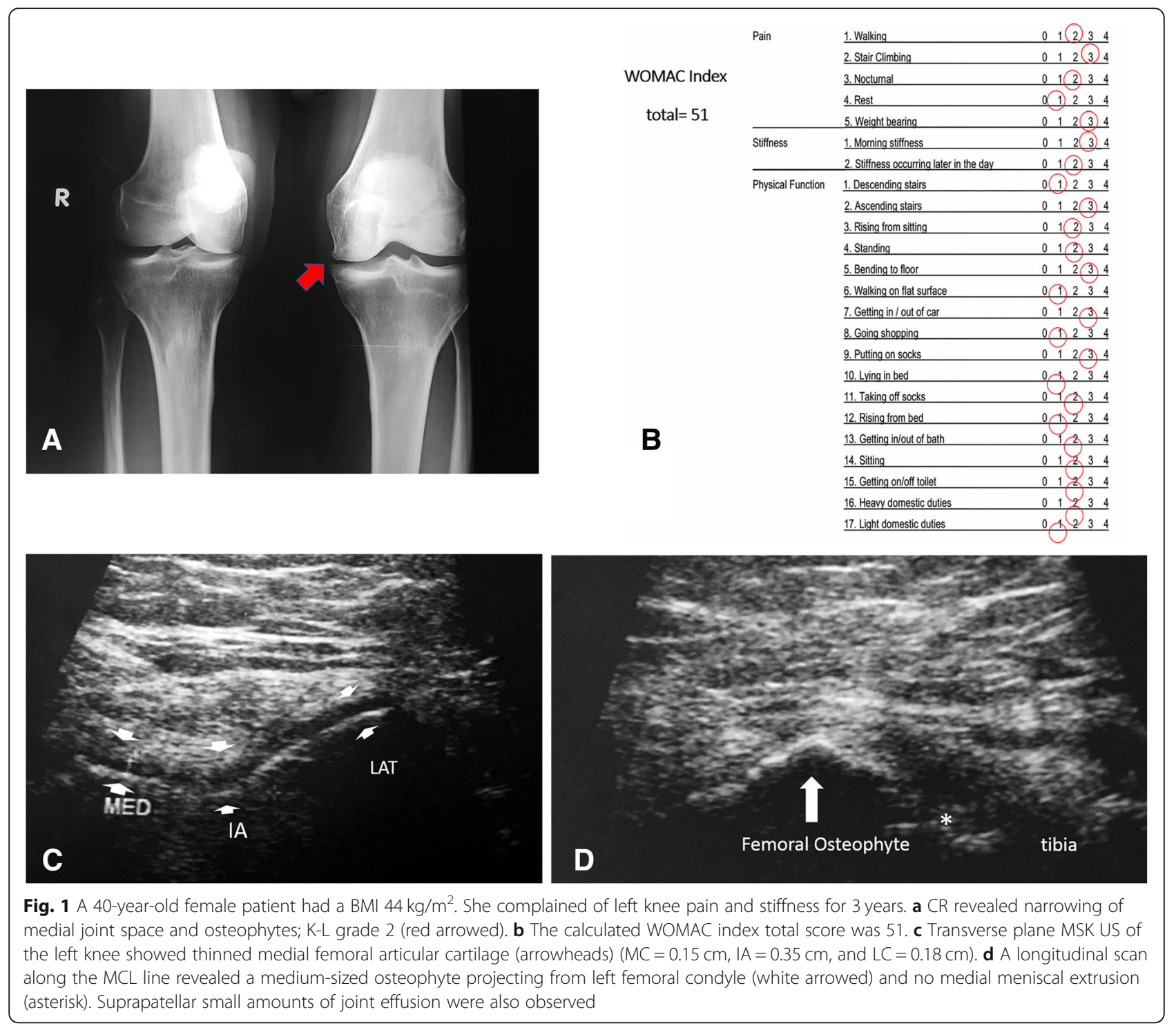

correlation with the pain subclass of the WOMAC. However, a significant inverse link between MC thickness and K-L score was found in the current work. Joint space narrowing is a primary feature of conventional radiography. Relevant studies have suggested a moderate correlation between radiographic joint space narrowing and loss of the articular cartilage [35]. In contrast, Kaban et al. [33] reported no statistically significant difference in terms of the mean cartilage thickness between the K$\mathrm{L}$ radiological grades $(p>0.05)$.

Table 3 Correlation between femoral cartilage thickness and WOMAC index subclasses

\begin{tabular}{|c|c|c|c|c|c|c|}
\hline & \multicolumn{2}{|l|}{$M C$} & \multicolumn{2}{|l|}{ IA } & \multicolumn{2}{|l|}{$\mathrm{LC}$} \\
\hline & $r$ & $p$ & $r$ & $p$ & $\bar{r}$ & $P$ \\
\hline Pain & -0.100 & 0.488 & 0.342 & $0.015^{*}$ & 0.137 & 0.342 \\
\hline Stiffness & -0.036 & 0.806 & 0.414 & $0.003^{* *}$ & 0.257 & 0.072 \\
\hline Physical function & -0.119 & 0.410 & 0.217 & 0.131 & -0.182 & 0.206 \\
\hline Total & -0.073 & 0.615 & 0.322 & $0.022^{*}$ & 0.49 & 0.735 \\
\hline BMI & 0.233 & 0.120 & 0.178 & 0.217 & 0.154 & 0.287 \\
\hline
\end{tabular}

*Correlation is significant at the 0.05 level (two-tailed)

${ }^{*}$ Correlation is significant at the 0.01 level (two-tailed) 


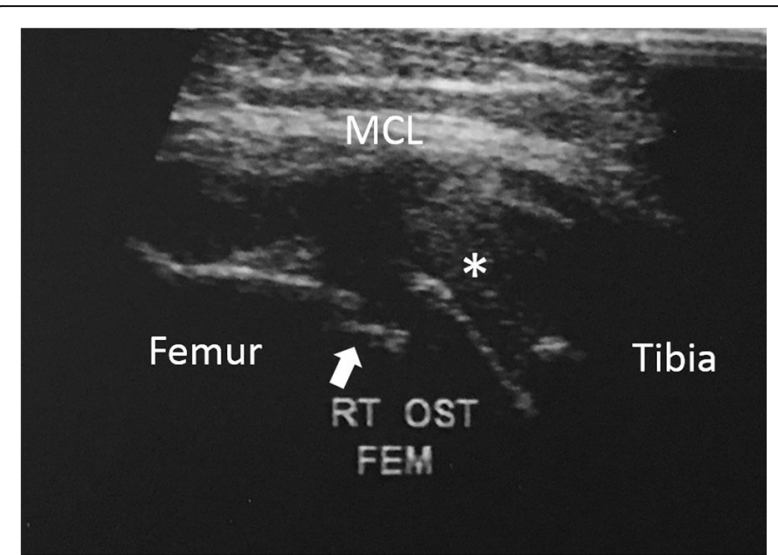

Fig. 2 A 60-year-old male patient complained of right knee stiffness. Longitudinal plane MSK US at the MCL revealed medial extrusion of the degenerated medial meniscus (asterisk) and a medium-sized femoral osteophyte (white arrowed)

In contrast, another study has reported that joint space narrowing is secondary to meniscal bulging rather than loss of hyaline cartilage [42]. This agreed with our study, as $40 \%$ of our patients had medial meniscal extrusion. This was supported by Bruyn et al.'s [43] study which stated that the medial meniscal extrusion is considered a signature feature of knee OA explained it by its close relationship with the medial collateral ligament. This was similar to the findings of Bevers et al. [44] study.

Moreover, our results agreed with previous observations that showed a decreased volume of the medial compartment of the knee when compared to the lateral compartment in patients with KOA [43-46].

The results of the current study are consistent with those of Abd El Monaem et al. [39], who reported that the mean thicknesses of the lateral and medial femoral cartilage were $2.0 \pm 0.3 \mathrm{~mm}$ and $1.9 \pm 0.3 \mathrm{~mm}$, respectively. Additionally, Naredo et al. [47] concluded that MSK US is a reproducible imaging tool for measuring femoral articular cartilage thickness in normal and moderately damaged knee joint cartilage. The thinner medial tibiofemoral and patellofemoral articular cartilages have been hypothesized to demonstrate an adaptive response to the higher pressure placed on this area during normal everyday weightbearing activities, such as standing and walking [48].

The current study had some limitations. First, the small sample was taken from a single center. Second, we only examined meniscal subluxation at the level of the medial collateral ligament (MCL) in the supine position. Third, we evaluated the global level of pain and its relation to the thickness of femoral articular cartilage, but we did not focus on specific physical activities. Finally,

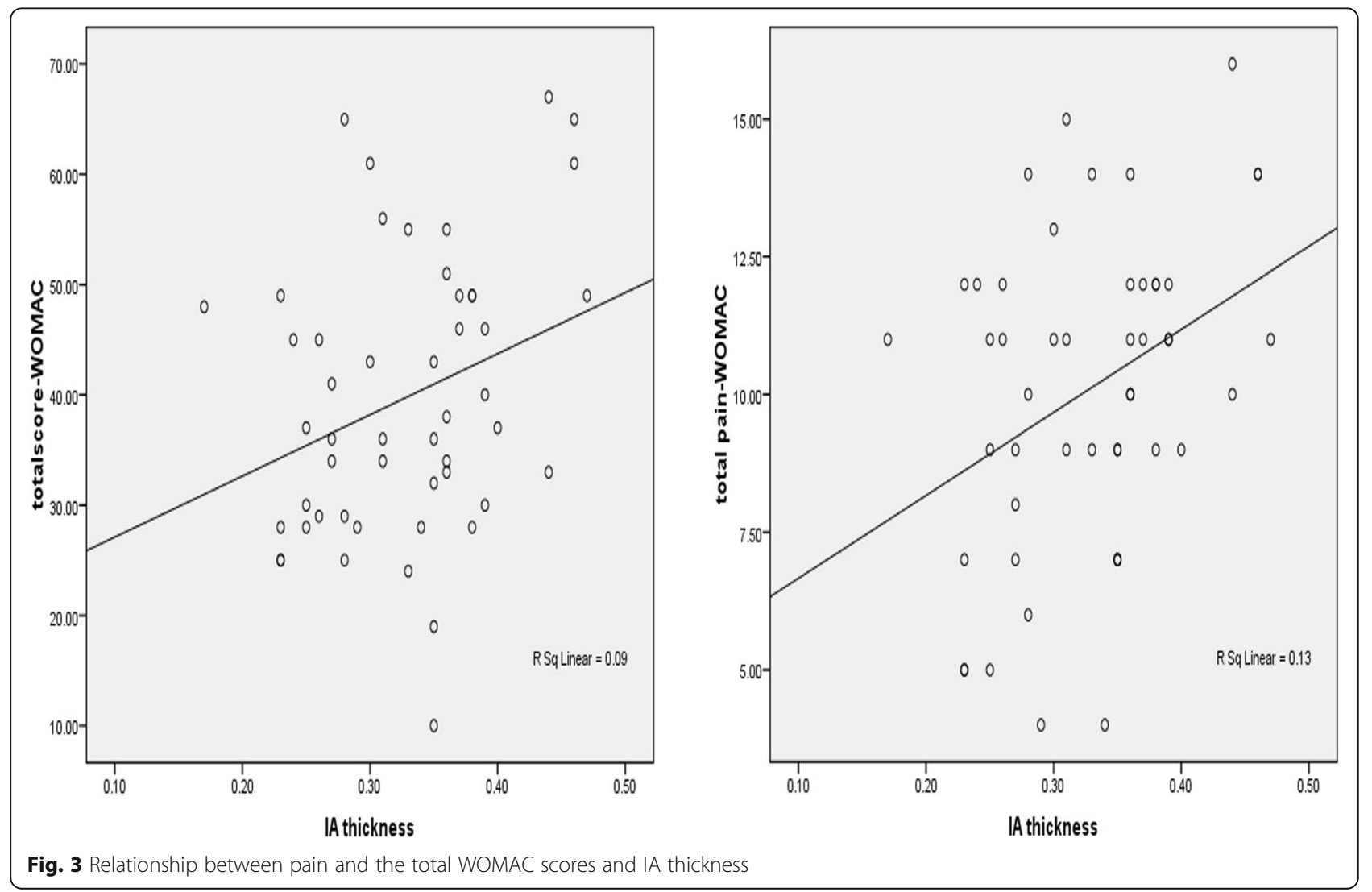


with technical errors, by keeping the knee in full flexion, it is possible to expose significant portions of the weight-bearing surface of the femoral articular cartilage. The main flaw of the MSK US was a limited acoustic window to visualize the articular cartilage owing to the inability of the US beam to penetrate the bony cortex as reported by Moller et al. [49].

\section{Conclusion}

In conclusion, MSK US is a non-invasive, widely available, and inexpensive technique. It can be performed promptly and is a radiation-free diagnostic test. In addition, MSK US is a reliable method for identifying knee effusion/synovitis, osteophytes, medial meniscal protrusion, Backer's cyst, and early structural change. A moderate correlation was observed between knee MSK US and WOMAC index subclasses.

\section{Abbreviations}

ACR: American College of Rheumatology; BMl: Body mass index; EULAR: European League Against Rheumatism; IA: Intercondylar notch area; K-L: Kellgren-Lawrence grading system; KOA: Knee osteoarthritis; LC: Lateral femoral condyle; MC: Medial femoral condyle; MCL: Medial collateral ligament; MRI: Magnetic resonance imaging; MSK US: Musculoskeletal ultrasound; OMERACT: Outcome Measures in Rheumatology; US: Ultrasound; WOMAC: Western Ontario and McMaster Universities Osteoarthritis Index

\section{Acknowledgements}

Not applicable.

\section{Authors' contributions}

With the submission of this manuscript, I would like to declare that all authors have contributed sufficiently to the scientific work regarding study concepts and design, clinical studies, collecting the data, statistical analysis, manuscript preparation, and editing. All authors of this paper have read and approved the final version submitted.

\section{Funding}

This study had no funding from any resource.

\section{Availability of data and materials}

The datasets used and/or analyzed during the current study are available from the corresponding author on reasonable request.

\section{Ethics approval and consent to participate}

This study was approved by the Research Ethics Committee of the Faculty of Medicine at Assiut University in Egypt in August 2015. All patients included in this study gave written informed consent to participate in this research.

\section{Consent for publication}

All patients included in this research gave written informed consent to publish the data contained within this study.

\section{Competing interests}

The authors declare that they have no competing interests.

\section{Author details}

'Diagnostic Radiology Department, Faculty of Medicine, Assiut University Hospital, Assiut University, Assiut, Egypt. ${ }^{2}$ Rheumatology and Rehabilitation Department, Assiut University Hospital, Assiut University, Assiut, Egypt.
Received: 6 June 2019 Accepted: 5 August 2019

Published online: 06 September 2019

\section{References}

1. Fibel KH, Hillstrom HJ, Halpern BC (2015) State-of-the-art management of knee osteoarthritis. World J Clin Cases. 3:89-101

2. Moyer RF, Ratneswaran A, Beier FB, Birmingham TB (2014) Osteoarthritis year in review 2014: mechanics-basic and clinical studies in osteoarthritis. Osteoarthritis Cartilage. 22:1989-2002

3. Nuki G (1999) Osteoarthritis: a problem of joint failure. Z.Rheumatol. 58: 142-147

4. Eyre DR (2004) Collagens and cartilage matrix homeostasis. Clin Orthop Relat Res. 427:S118-S122

5. Eyles J, Lucas BR, Hunter DJ (2013) Targeting care: tailoring nonsurgical management according to clinical presentation. Rheum Dis Clin North Am. 39:213-233

6. Bellamy N, Buchanan WW, Goldsmith CH, Campbell J, Stitt LW (1988) Validation study of WOMAC: a health status instrument for measuring clinically important patient relevant outcomes to antirheumatic drug therapy in patients with osteoarthritis of the hip or knee. J Rheumatol. 15: 1833-1840

7. Gandek B (2015) Measurement properties of the Western Ontario and McMaster Universities Osteoarthritis index: a systematic review. Arthritis Care Res. 67:216-229

8. Ackerman IN, Tacey MA, Ademi Z, Bohensky MA, Liew D, Brand CA (2014) Using WOMAC index scores and personal characteristics to estimate assessment of quality of life utility scores in people with hip and knee joint disease. Qual Life Res. 23:2365-2374

9. Paradowski PT (2014) Osteoarthritis of the knee: assessing the disease. Health Care Current Reviews 2:e103. https://doi.org/10.4172/hccr.1000e103

10. Spector TD, Hart DJ, Byrne J et al (1993) Definition of osteoarthritis of the knee for epidemiological studies. Ann Rheum Dis. 52:790-794

11. Kellgren JH, Lawrence JS (1957) Radiological assessment of osteoarthrosis. Ann Rheum Dis. 16:494-502

12. Bauer DC, Hunter DJ, Abramson SB et al (2006) Classification of osteoarthritis biomarkers: a proposed approach. Osteoarthritis Cartilage. 14:723-727

13. Huang M, Schweitzer M (2014) The role of radiology in the evolution of the understanding of articular disease. Radiology. 273:S1-S22

14. Roemer FW, Eckstein F, Hayashi D et al (2014) A The role of imaging in osteoarthritis. Best Pract Res Clin Rheumatol. 28:31-60

15. Shapiro LM, McWalter EJ, Son MS et al (2014) Mechanisms of osteoarthritis in the knee: MR imaging appearance. J Magn Reson Imaging. 39:1346-1356

16. Ahmed R, Nazarian L (2010) Overview of musculoskeletal sonography. Ultrasound Quarterly 26:27-35

17. Ben Abdelghani $K$, Miladi S, Souabni $L$ et al (2015) Role of ultrasound in assessing remission in rheumatoid arthritis. Diagn Interv Imaging. 96:3-10

18. lagnocco A, Ceccarelli F, Perricone C et al (2014) The use of musculoskeletal ultrasound in a rheumatology outpatient clinic. Med Ultrason. 16:332-335

19. Sconfienza LM, Albano D, Allen G, Bazzocchi A, Bignotti B, Chianca $V$ et al (2018) Clinical indications for musculoskeletal ultrasound updated in 2017 by European Society of Musculoskeletal Radiology (ESSR) consensus. European radiology. 28(12):5338-5351

20. lagnocco A, Naredo E (2017) Ultrasound of the osteoarthritic joint. Clin Exp Rheumatol. 35:527-534

21. Keen HI, Wakefield RJ, Conaghan PGA (2009) Systematic review of ultrasonography in osteoarthritis. Ann Rheum Dis. 68:611-619. https://doi. org/10.1136/ard.2008.102434

22. Moller I, Janta I, Backhaus M, Ohrndorf S, Bong DA, Martinoli C et al (2017) The 2017 EULAR standardised procedures for ultrasound imaging in rheumatology. Annals of the rheumatic diseases. 76(12):1974-1979

23. Altman R, Asch E, Bloch D et al (1986) Development of criteria for the classification and reporting of osteoarthritis. Classification of osteoarthritis of the knee. Diagnostic and Therapeutic Criteria Committee of the American Rheumatism Association. Arthritis Rheum 29:1039-1049

24. Katz JN, Barrett J, Mahomed NN, Baron JA, Wright RJ et al (2004) Association between hospital and surgeon procedure volume and the outcomes of total knee replacement. J Bone Joint Surg Am 86:1909-1916

25. Tuzun EH, Eker L, Aytar A et al (2005) Acceptability, reliability, validity, and responsiveness of the Turkish version of WOMAC osteoarthritis index. Osteoarthritis Cartilage 13:28-33 
26. Escobar A, Quintana JM, Bilbao A et al (2007) Responsiveness and clinically important differences for the WOMAC and SF-36 after total knee replacement. Osteoarthritis Cartilage 15:273-280

27. Salaff F, Leardini G, Canesi B et al (2003) Reliability and validity of the Western Ontario and McMaster Universities (WOMAC) Osteoarthritis Index in Italian patients with osteoarthritis of the knee. Osteoarthritis Cartilage 11:551-560

28. Saarakkala S, Waris P, Waris V et al (2012) Diagnostic performance of knee ultrasonography for detecting degenerative changes of articular cartilage. Osteoarthritis and Cartilage 20:376-381

29. Yoon $\mathrm{CH}$, Kim HS, Ju JH et al (2008) Validity of the sonographic longitudinal sagittal image for assessment of the cartilage thickness in the knee osteoarthritis. Clin Rheumatol 27:1507-1516

30. D'Agostino MA, Conaghan P, Le Bars M et al (2005) EULAR report on the use of ultrasonography in painful knee osteoarthritis. Part 1: prevalence of inflammation in osteoarthritis. Ann Rheum Dis. 64:1703-1709

31. Wakefield RJ, Balint PV, Szkudlarek M et al (2005) Musculoskeletal ultrasound including definitions for ultrasonographic pathology. J Rheumatol. 32:2485-2487

32. Woolf AD, Pfleger B (2003) Burden of major musculoskeletal conditions. Bull World Health Organ. 81:646-656

33. Kaban N, Tekeoğlul HH (2016) Ultrasonographic characteristics of femoral trochlear cartilage in patients with knee osteoarthritis. Erciyes Med J. 38: 127-133. https://doi.org/10.5152/etd.2016.0084

34. Zheng $\mathrm{H}$, Chen $\mathrm{C}$ (2015) Body mass index and risk of knee osteoarthritis: systematic review and meta-analysis of prospective studies. BMJ open 5 e007568. https://doi.org/10.1136/bmjopen-2014-007568

35. Malas FÜ, Kara M, Kaymak B, et al. (2014) Ultrasonographic evaluation in symptomatic knee osteoarthritis: clinical and radiological correlation. Int J Rheum Dis. 17:536-540. doi: https://doi.org/10.1111/1756-185X.12190. Epub 2013 Oct 29.

36. Hill CL, Gale DG, Chaisson CE et al (2001) Knee effusion, popliteal cysts, and synovial thickening: association with knee pain in osteoarthritis. J Rheumatol. 28:1330-1337

37. Chen YJ, Chen CH, Wang CL et al (2015) Association between the severity of femoral condylar cartilage erosion related to knee osteoarthritis by ultrasonographic evaluation and the clinical symptoms and functions. Arch Phys Med Rehabil. 96:837-844

38. Razek AA, El-Basyouni SR (2016) Ultrasound of knee osteoarthritis: interobserver agreement and correlation with Western Ontario and McMaster Universities Osteoarthritis. Clin Rheumatol. 35:997-1001. doi: https://doi.org/10.1007/s10067-015-2990-2. Epub 2015 Jun 20.

39. Abd El Monaem SM, Hashaad NI, Ibrahim NH (2017) Correlations between ultrasonographic findings, clinical scores, and depression in patients with knee osteoarthritis. Eur J Rheumatol 4:205-209. https://doi.org/10.5152/ eurjrheum.2017.160097

40. Cubukcu D, Sarsan A, Alkan H (2012) Relationships between pain, function and radiographic findings in osteoarthritis of the knee: a cross-sectional study. Arthritis. 22:1-5

41. Serban O, Porojan M, Deac M et al (2016) Pain in bilateral knee osteoarthritis - correlations between clinical examination, radiological, and ultrasonographical findings. Med Ultrason. 18:318-325. https://doi.org/1 0.11152/mu.2013.2066.183.pin

42. Gale DR, Chaisson CE, Totterman SM et al (1999) Meniscal subluxation: association with osteoarthritis and joint space narrowing. Osteoarthritis Cartilage 7:526-532

43. Bruyn GA, Naredo E, Damjanov N et al (2016) Ultrasound Task Force. An OMERACT reliability exercise of inflammatory and structural abnormalities in patients with knee osteoarthritis using ultrasound assessment. Ann Rheum Dis 75:842-846. https://doi.org/10.1136/annrheumdis-2014-206774

44. Bevers K, Zweers MC, van den Ende CH et al (2012) Ultrasonographic analysis in knee osteoarthritis: evaluation of inter-observer reliability. Clin Exp Rheumato 30:673-678

45. Ekim AA, Hamarat H, Musmul A (2017) Relationship between Q-angle and articular cartilage in female patients with symptomatic knee osteoarthritis: ultrasonographic and radiologic evaluation. Arch Rheumatol. 32:347-352

46. Jones G, Glisson M, Hynes K et al (2000) Sex and site differences in cartilage development: a possible explanation for variations in knee osteoarthritis in later life. Arthritis Rheum. 43:2543-2549
47. Naredo E, Acebes C, Möller I, et al. (2009) Ultrasound validity in the measurement of knee cartilage thickness. Ann Rheum Dis. 68:1322-1327. doi: https://doi.org/10.1136/ard.2008.090738. Epub 2008 Aug 6.

48. Waterton JC, Solloway S, Foster JE et al (2000) Diurnal variation in the femoral articular cartilage of the knee in young adult humans. Magn Reson Med. 43:126-132

49. Möller DB, Naredo E, Filippucci E, Carrasco I, Moragues C, lagnocco A (2008) Ultrasound in the study and monitoring of osteoarthritis. Osteoarthritis and Cartilage. 16:S4-S7. https://doi.org/10.1016/j.joca.2008.06.005

\section{Publisher's Note}

Springer Nature remains neutral with regard to jurisdictional claims in published maps and institutional affiliations.

\section{Submit your manuscript to a SpringerOpen ${ }^{\circ}$ journal and benefit from:}

- Convenient online submission

- Rigorous peer review

- Open access: articles freely available online

- High visibility within the field

- Retaining the copyright to your article

Submit your next manuscript at $\boldsymbol{\nabla}$ springeropen.com 